\title{
Cladding-pumped 70-kW-peak-power 2-ns-pulse Er-doped fiber amplifier
}

M. M. Khudyakov, M. M. Bubnov, A. K. Senatorov, D. S. Lipatov, A. N. Guryanov, et al.

M. M. Khudyakov, M. M. Bubnov, A. K. Senatorov, D. S. Lipatov, A. N. Guryanov, A. A. Rybaltovsky, O. V. Butov, L. V. Kotov, M. E. Likhachev, "Cladding-pumped 70-kW-peak-power 2-ns-pulse Er-doped fiber amplifier," Proc. SPIE 10512, Fiber Lasers XV: Technology and Systems, 1051216 (26 February 2018); doi: 10.1117/12.2290837

SPIE. Event: SPIE LASE, 2018, San Francisco, California, United States 


\title{
Cladding-Pumped 70-kW-Peak-Power 2-ns-Pulse Er-doped Fiber Amplifier
}

\author{
M.M. Khudyakov ${ }^{1,2 *}$, M.M. Bubnov ${ }^{1}$, A.K. Senatorov ${ }^{1}$, D.S. Lipatov ${ }^{3}$, A.N. Guryanov ${ }^{3}$, \\ A.A. Rybaltovsky ${ }^{4}$, O.V. Butov ${ }^{4}$, L.V.Kotov ${ }^{5}$, M.E. Likhachev ${ }^{1}$ \\ ${ }^{1}$ Fiber Optics Research Center, Russian Academy of Sciences, 38 Vavilova street, 119333 Moscow, \\ Russian Federation; ${ }^{2}$ Moscow Institute of Physics and Technology (State University), Institutskii \\ per. 9,141700 Dolgoprudnyi, Moscow region, Russian Federation; ${ }^{3}$ G.G. Devyatykh Institute of \\ Chemistry of High-Purity Substances, Russian Academy of Sciences, 49 Tropinina street, 603950 \\ Nizhnii Novgorod, Russian Federation; ${ }^{4}$ Kotel'nikov Institute of Radio Engineering and Electronics, \\ Russian Academy of Sciences, Mokhovaya 11-7, Moscow 125009, Russian Federation, ${ }^{5}$ College of \\ Optical Sciences, University of Arizona, 1630 E. University Blvd.Tucson, AZ 85721 USA
}

\begin{abstract}
An all-fiber pulsed erbium laser with pulse width of 2.4 ns working in a MOPA configuration has been created. Cladding pumped double clad erbium doped large mode area fiber was used in the final stage amplifier. Peculiarity of the current work is utilization of custom-made multimode diode wavelength stabilized at $981 \pm 0.5 \mathrm{~nm}$ - wavelength of maximum absorption by Er ions. It allowed us to shorten Er-doped fiber down to $1.7 \mathrm{~m}$ and keep a reasonably high pump-to signal conversion efficiency of $8.4 \%$. The record output peak power for all-fiber amplifiers of $84 \mathrm{~kW}$ was achieved within $1555.9 \pm 0.15 \mathrm{~nm}$ spectral range.
\end{abstract}

Keywords: erbium doped fiber amplifier, double clad, high peak power, large mode area

\section{INTRODUCTION}

High peak power ns-pulse fiber lasers operating near $1.55 \mu \mathrm{m}$ are perspective source for remote sensing, frequency conversion and micromachining. To date the highest peak power of $40 \mathrm{~kW}$ in $5 \mathrm{~ns}$ pulses was demonstrated using largemode-area (LMA) silica-based Er-Yb fiber ${ }^{1}$. However the laser scheme used in this work contained bulk elements required to filter our luminescence near $1 \mu \mathrm{m}$ from the first preamplifier stage. Also the pump-to-signal conversion efficiency achieved by authors was quite low, about $4.8 \%$. A higher peak power of $128 \mathrm{~kW}$ can be obtained using LMA Er-Yb phosphate fiber ${ }^{2}$ with the price of further reduction of pump-to-signal conversion efficiency down to $1.5 \%$. Moreover, the result achieved in ${ }^{2}$ had no potential for scaling due to already existent problems with thermal effects at high pump powers.

Another perspective approach is cladding pumped $\mathrm{Yb}$-free LMA Er-doped fiber amplifier (EDFA). In this case the record pulse energy of $1 \mathrm{~mJ}$ in $100 \mathrm{~ns}$ pulses was demonstrated ${ }^{3}$. The maximum peak power of $13 \mathrm{~kW}$ was limited by amplified spontaneous emission (ASE), which was appeared due to limited stored energy in the EDFA. Using the same amplifier design we have built a $2 \mathrm{~ns}$ pulsed laser with a maximum peak power of $30 \mathrm{~kW}$ ( $24 \mathrm{~kW}$ coupled to hollow-core fiber), that was used as pump source for hydrogen-filled hollow core silica fiber to achieve peak power at $4.4 \mu \mathrm{m}$ of $0.6 \mathrm{~kW}$. ${ }^{4,5}$

The aim of the current work was optimization of the amplifier design to achieve the maximum peak power for the cladding pumped Yb-free Er-doped fiber.

*DAngeL.74@gmail.com

Fiber Lasers XV: Technology and Systems, edited by Ingmar Hartl, Adrian L. Carter, Proc. of SPIE Vol. 10512, 1051216 - @ 2018 SPIE · CCC code: 0277-786X/18/\$18 · doi: 10.1117/12.2290837 


\section{SETUP}

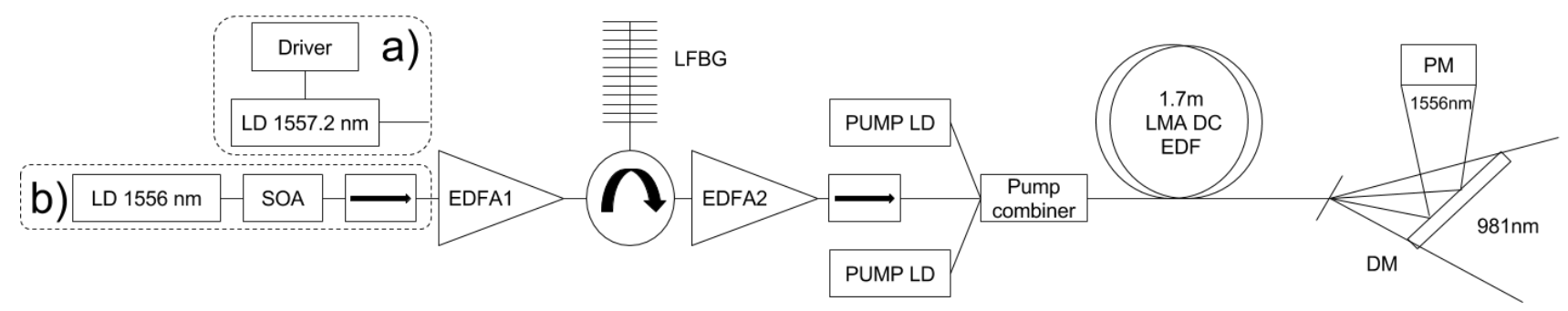

Figure 1. MOPA laser setup with a) electrically driven LD and b) SOA for shaping pulses.

The nanosecond laser in the current work has master oscillator with power amplifier (MOPA) configuration (see Figure 1a)). The first version of master oscillator was based on distributed feedback semiconductor(DFB) laser diode (LD) electrically driven at repetition rate of $25 \mathrm{kHz}$ to produce $2 \mathrm{~ns}$ pulses with peak wavelength of $1557.22 \mathrm{~nm}$. This resulted in several peaks in output spectrum of the diode see Figure 2a)). Thus in the second version of the scheme (Figure 1b)) we used semiconductor optical amplifier (SOA) to produce $2.4 \mathrm{~ns}$ pulses from continuously operating LD with central wavelength of $1555.97 \mathrm{~nm}$ (Figure $2 \mathrm{~b}$ )) at average power of $\sim 0.5-1 \mathrm{~mW}$. To protect the SOA from backwards propagating ASE we used an isolator. These pulses were amplified by two stages Er-doped fiber amplifiers (EDFA1, EDFA2). A narrowband (FWHM $\sim 0.08 \mathrm{~nm}$ ) spectral filter, based on circulator with a long length Bragg grating (LFBG) was used to filter out ASE after the first stage (in both cases input power at EDFA1 was orders of magnitude lower than saturation power of the amplifier). The EDFA2 delivered pulses with average power of $10 \mathrm{~mW}$ ( $200 \mathrm{~W}$ of peak power). Part of power between pulses was controlled by integrating photodetector ${ }^{3}$ and was less than $3 \%$ at all pump powers. The seed was coupled through isolator and pump combiner into the power amplifier stage.

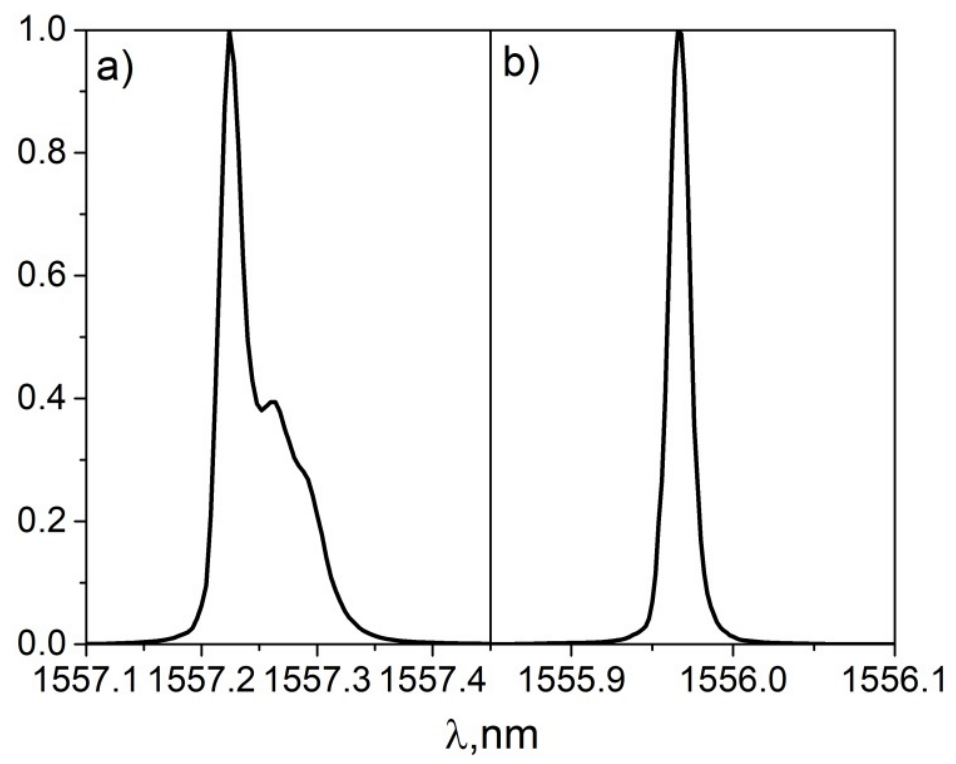

Figure 2. Normalized spectrum of pulses produced by a) electrically driven laser diode and b) SOA

The power amplifier was based on large mode area double clad cladding pumped Er-doped fiber (LMA DC EDF). The preform was manufactured by modified chemical vapor deposition technique. It's core was doped with $0.1 \mathrm{~mol} \%$ of $\mathrm{Er}^{2} \mathrm{O}^{3}$ in $\mathrm{P}^{2} \mathrm{O}^{5}-\mathrm{Al}^{2} \mathrm{O}^{3}-\mathrm{SiO}^{2}$ glass matrix. It was polished into a square and drown into a fiber with outer dimensions of $110 \times 110$ $\mu \mathrm{m}$. The core diameter was $35 \mu \mathrm{m}$, calculated cut-off wavelength was about $1650 \mathrm{~nm}$ and mode field diameter at $1 / \mathrm{e}^{2}$ was calculated to be $24.7 \mu \mathrm{m}$ (see Figure 3a),b)). The fiber was coated with low-index polymer, which provided NA of 0.46. Measured small signal absorption from the cladding at $981 \mathrm{~nm}$ was $3 \mathrm{~dB} / \mathrm{m}$ (Figure $3 \mathrm{c}$ )). In the current work we have replaced standard wavelength stabilized diodes at $976 \mathrm{~nm}$ by a two $24 \mathrm{~W}$ multimode laser diodes from BWT Beijing 
company with central wavelength shifted to the maximum of Er ions absorption - the most power was within $981 \pm 0.5 \mathrm{~nm}$ (Figure 3c)). A higher clad absorption at this wavelength allowed us to noticeable shorten the Er-doped fiber length without strong degradation of pump-to-signal conversion efficiency. We used $1.9 \mathrm{~m}$ long Er-doped fiber in the first experiment with laser based on modulated DFB diode (Figure 1a))and $1.7 \mathrm{~m}$ in the laser with modulation by SOA (Figure 1b)). Copropagating pumping of the Er-doped fiber was used. Total pump-to-signal conversion efficiency was $8.4 \%$ relative to the launched pump power for both versions of lasers. The output end of the Er-doped fiber was angle-cleaved to prevent backscattering. Dichroic mirror (DM) was used to separate amplified pulses from unabsorbed pump. Output power was measured by power meter (PM). Part of power between pulses was controlled by integrating photodetector.
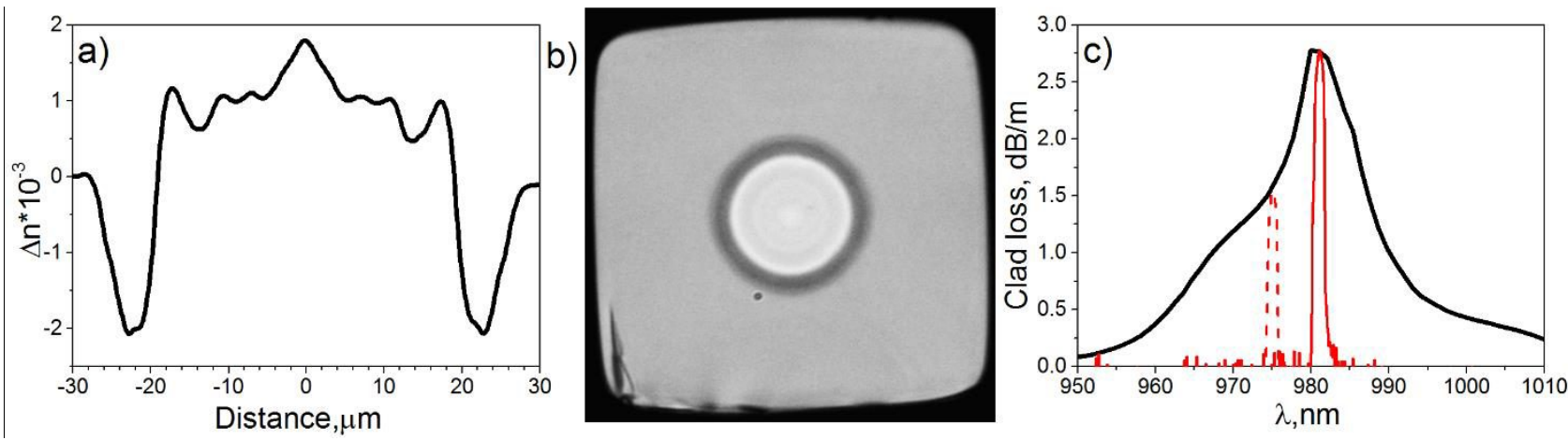

Figure 3. a) Fiber refractive index profile of LMA DC EDF; b) optical image of a fiber end facet; c) fiber clad absorption peak at $981 \mathrm{~nm}$ and PUMP LD spectrum at $976 \mathrm{~nm}$ (dashed red line) and $981 \mathrm{~nm}$ (red line).

\section{RESULTS}

The first version of the laser had a little bit longer active fiber and significantly worse spectrum. Therefore, the four wave mixing (FWM) threshold (dramatic increaser of part of power contained in peaks caused by FWM) has been achieved at only $50 \mathrm{~kW}$ (Figure 4c)). At maximum pump power $13 \%$ of output power is contained in peaks caused by FWM, which corresponds to $70 \mathrm{~kW}$ of peak power in band $(1557.3 \pm 0.2 \mathrm{~nm})$.

The second version of laser had shorter active fiber $(1.7 \mathrm{~m})$, thus the FWM threshold was achieved at maximum pump power of $48.6 \mathrm{~W}$. At $48.6 \mathrm{~W}$ of pump power less than $2 \%$ of output power were contained in peaks caused by FWM, therefore the peak power was $84 \mathrm{~kW}$. It is worth noting that output spectra of these lasers have FWM peaks at significantly different wavelengths. Output spectra of the first version had additional peaks at $1550 \mathrm{~nm}$ and $1567 \mathrm{~nm}$, which are caused by additional peaks at diode output spectrum which could not be completely filtered out by the bragg grating. We suggest that a much better output spectrum in the case of the second laser is caused by single-frequency operation regime (modulation by SOA results in generation of spectral-limited pulses in contract to direct modulation of DFB diode, when new spectral components appears due to change of current in DFB diode). 

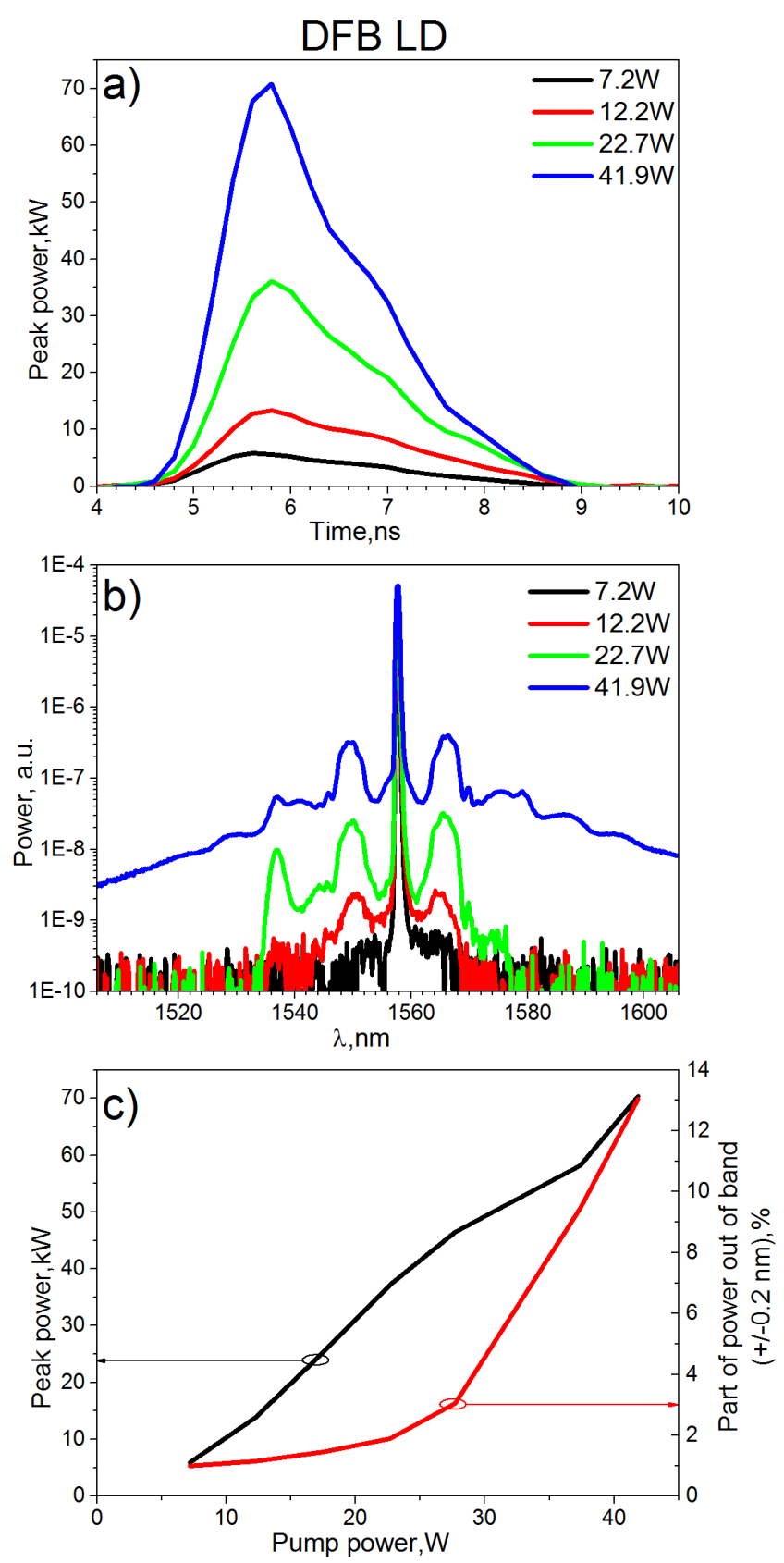
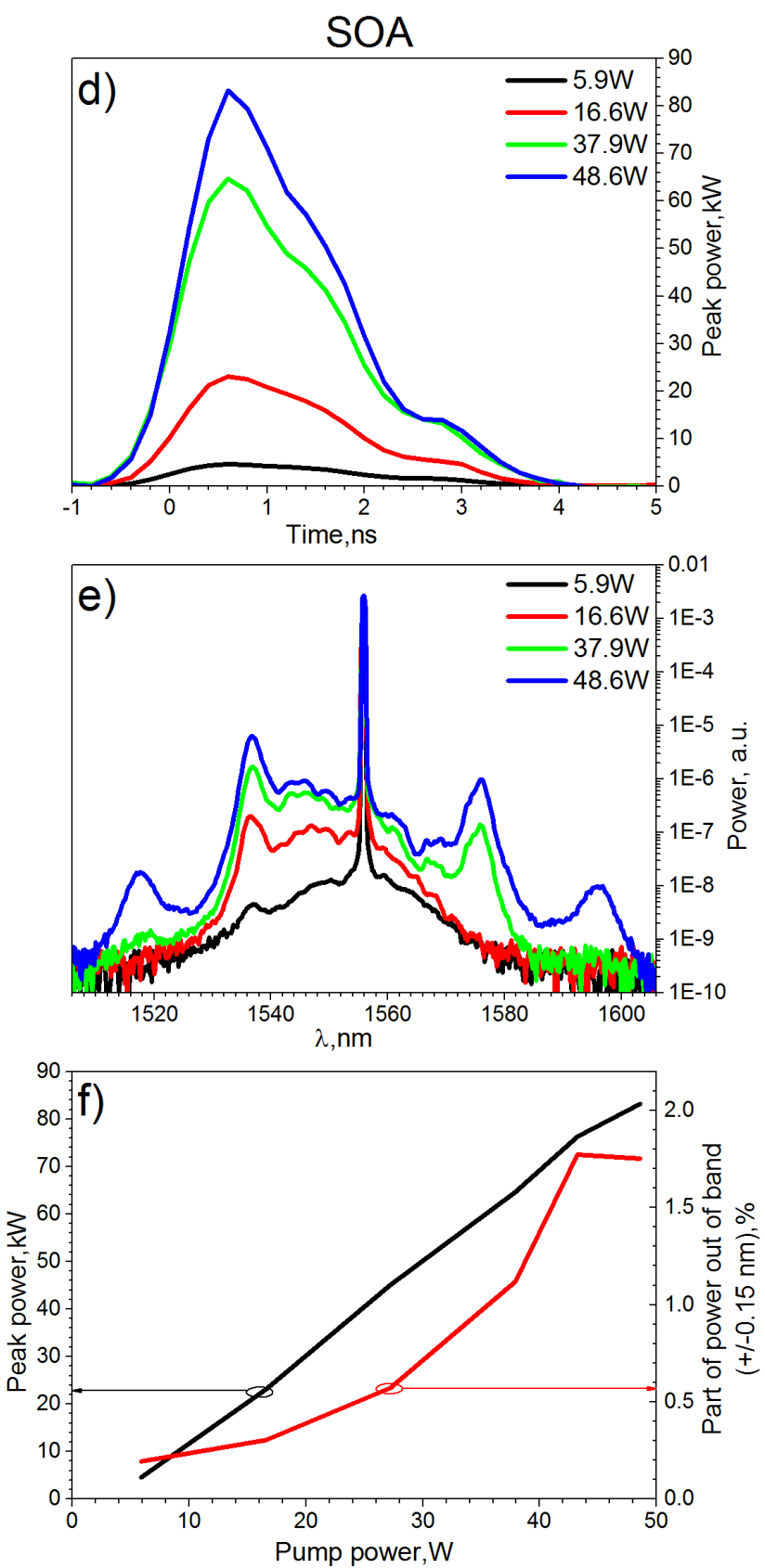

Figure 4. a) Temporal profile: b) Spectra; c) Peak power in band and part of power out of band vs pump power for laser based on direct modulation of DFB-LD; d),e),f) - the same for the second version of the laser based on SOA.

\section{CONCLUSION}

We have demonstrated output peak power of $84 \mathrm{~kW}$, which, to the best of our knowledge, is the highest peak for Er-doped $\mathrm{Yb}$-free all-fiber laser with pulses longer than one nanosecond. It is only 33\% lower than the peak power demonstrated in $\mathrm{Er}-\mathrm{Yb}$ codoped phosphate glass core fiber amplifier. Total pump-to-signal conversion efficiency was $8.4 \%$, which is more than 5 times higher than demonstrated in Er-Yb phosphate amplifier This result can be further scaled by reducing active fiber length and adding pump power or input power from preamplifier.

The study was supported by the Russian Science Foundation (RSF) (№16-19-10513) 


\section{REFERENCES}

[1] Zhao, Z., Xuan, H., Igarashi, H., Ito, S., Kakizaki, K. and Kobayashi, Y., "Single frequency, 5 ns, $200 \mu$ J, 1553 nm fiber laser using silica based Er-doped fiber," Opt. Express 23(23), 29764 (2015).

[2] Petersen, E., Shi, W., Chavez-Pirson, A. and Peyghambarian, N., "High peak-power single-frequency pulses using multiple stage, large core phosphate fibers and preshaped pulses," Appl. Opt. 51(5), 531 (2012).

[3] Kotov, L., Likhachev, M., Bubnov, M., Medvedkov, O., Lipatov, D., Guryanov, A., Zaytsev, K., Jossent, M. and Février, S., "Millijoule pulse energy 100-nanosecond Er-doped fiber laser," Opt. Lett. 40(7), 1189 (2015).

[4] Gladyshev, A., Kosolapov, A. F., Khudyakov, M. M., Yatsenko, Y. P., Senatorov, A. K., Kolyadin, A. N., Krylov, A. A., Plotnichenko, V. G., Likhachev, M. E., Bufetov, I. A. and Dianov, E. M., "Raman Generation in 2.9 - $3.5 \mu \mathrm{m}$ Spectral Range in Revolver Hollow-Core Silica Fiber Filled by H_2/D_2 Mixture," Conf. Lasers Electro-Optics, STu1K.2 (2017).

[5] Gladyshev, A., Kosolapov, A. F., Khudyakov, M., Yatsenko, Y. P., Kolyadin, A. N., Krylov, A. A., Pryamikov, A., Biriukov, A., Likhachev, M. E. and Bufetov, I. A., "4.4 $\mu$ m Raman Laser Based on Hydrogen-Filled HollowCore Silica Fiber," CLEO Sci. Innov., JTh5A (2017). 